\title{
INVESTIGATION ON THE DIAGNOSIS OF SIMPLE AND COMBINES MECHANICAL FAULTS IN ASYNCHRONOUS MOTOR BASED ELECTRIC DRIVES
}

\author{
${ }^{1}$ Bouras A. Karim, ${ }^{1}$ Bouras Slimane, \\ ${ }^{2}$ Hadjadj A. Elias, ${ }^{1}$ Benamira Nadir and ${ }^{2}$ Kerfali Samir \\ ${ }^{1}$ Electromechanical Systems Laboratory, BadjiMokhtar University, Annaba, Algeria \\ ${ }^{2}$ Laboratory of Electromechanical Engineering, BadjiMokhtar University, Annaba, Algeria
}

Received 2014-01-17; Revised 2014-03-21; Accepted 2014-04-11

\begin{abstract}
In this study, the problems of mechanical unbalance, parallel and angular misalignments and their combinations are analyzed experimentally. Such frequent defects in the drives mainly in the major powers are also responsible for the bearings degradation. However, they have not raised the attention of researchers, given the complexity of their modeling. The combination of the phasic current signal analysis and the neutral current by the FFT supplemented by visual interpretation of patterns models these defects resulting from the 3D representation. The results obtained by using the proposed method show the efficiency to provide an accurate diagnosis of the state of the electric drive undergoing to isolated and combined mechanical defaults to a maintenance staff not necessarily expert of mechanical failure. The innovative approach validated experimentally on a $5.37 \mathrm{KW}$ motor, offers an efficiency to provide an accurate diagnosis to a maintenance staff not necessarily composed of experts in this field.
\end{abstract}

Keywords: Induction Motor, Diagnosis, Multiple Mechanical Defects, MCSA, Neutral Current, Pattern Recognition

\section{INTRODUCTION}

The monitoring of electrical drives has interested many researchers so far (Sethom and Ghedamsi, 2012; Li and Meshefske, 2006; Bindus and Vinod, 2014; Pandey et al., 2012). As provided in Thorsen and Dalva (1995), Bonnett and Yung (2008), Thorsen and Dalva (1998), the repartition of many older publications on the defects of high power asynchronous machines has changed due to the motors production conditions. The unbalance, misalignment or their fusion that affects rotating machines, particularly those that are subject to considerable mechanical stress, generate mechanical vibration (Xu and Marangoni, 1994; Scheffer and Girdhar, 2004). They are considered as the main causes of other mechanical and electrical defects. The extensive studies that have been carried out by researchers using vibration analysis for the study of unbalance and misalignment have shown the complexity of diagnosis with vibration analysis. As reported in Thomson and Fenger (2001), Martınez-Morales et al. (2010), the high sensitivity of the current towards the torque variations sensed by the asynchronous motor and consequently towards simple and multiple mechanical defects that induce them, makes from its analysis an extremely powerful investigation tool. This paper tends toward an experimental approach for the diagnosis and detection of the aforementioned mechanical anomalies. Using signal processing, this approach is based on the knowledge of the healthy system's behavior which is then compared with the signals measured during different tests of the machine degradation (Concari et al., 2010; Medoued et al., 2009). Compared to previous works, this experimental research uses a combination of techniques by analyzing the phasic current (Kazzaz and Singh, 2003); Oumaamar et al. (2009) insufficiently developed when it comes to Corresponding Author: Bouras A. Karim, Electromechanical Systems Laboratory, BadjiMokhtar University, Annaba, Algeria 
unbalance, misalignment and especially their combinations. To reduce the overlapping frequencies that can coexist in the spectra when it comes to these deficiencies, a content analysis of the signal information of the current flow in the neutral conductor is conducted (Oumaamar et al., 2007). Then, to distinguish between the defects signatures, this technique is supported by a $3 \mathrm{D}$ representation of the square of the intensity of the motor supply current which, hitherto, has been subjected only to the treatment of the short circuits stator windings and rotor bars breaks (Martins et al., 2011; Pires et al., 2010). The results obtained are satisfactory. They can witness the robustness and effectiveness of this technique without a physical contact and through a remote monitoring of unique and multiple mechanical defects.

\section{THEORETICAL CONTEXT}

\subsection{The Effects of the Mechanical Faults on the Spectrum of the Current}

The results mentioned in several articles have shown that the imbalance and misalignment can be detected from the motor's vibration (Patel and Darpe, 2009; Sekhar and Prabhu, 1995; Wongsuwan et al., 2006) and electric measurements (Cameron et al., 1986).

These single or combined mechanical defects generate an eccentricity in the air gap affecting a variation in the motor's inductance. Consequently, a variation of the magnetic flux that contributes in modifying the supply current spectrum (Dorrell et al., 1997; Chaudhury et al., 2013; Sahraoui et al., 2008) compared to that of the healthy drive motor Equation 1:

$$
\Phi(\mathrm{t})=\Phi_{\mathrm{s}} \cos \left(\omega_{\mathrm{s}} \mathrm{t}\right)+\Phi_{\mathrm{r}} \cos \left(\omega_{\mathrm{s}} \mathrm{t}+\mathrm{m} \cdot \cos \left(\omega_{\mathrm{c}} \mathrm{t}\right)-\varphi_{\mathrm{r}}\right)
$$

The induced tension $\mathrm{V}_{\mathrm{i}}(\mathrm{T})$ corresponding with this flux is Equation 2:

$$
V_{i}(t)=d \Phi / d t
$$

\section{So:}

$$
V_{i}(t)=-\omega_{s} \Phi_{s} \sin \left(\omega_{s} t\right)-\omega_{s} \Phi_{r} \sin \left(\omega_{s} t+m \cdot \cos \left(\omega_{c} t\right)-\varphi_{r}\right)
$$

Consequently, the stator current modulated in phase $\mathrm{i}_{\mathrm{t} 0}(\mathrm{~T})$ for an arbitrary phase in the presence of an oscillating torque is expressed by Equation 3:

$$
i_{t 0}(T)=i_{s}(T)+i_{r}(T)
$$

So:

$$
i_{t 0}(T)=I_{s} \sin \left(\omega_{s} t\right)+I_{r} \sin \left(\omega_{s} t+m \cdot \cos \left(\omega_{c} t-\varphi A\right)-\varphi_{r}\right)
$$

Where:

$\varphi_{\mathrm{A}}=$ Denotes the phase angle of the modulation.

This shows that the fundamental component of current to is $(t)$ the sum of two components: The term $(t)$ results of the stator magneto motive force and it is not modulated. The Term ir (t), which is a direct consequence of the rotor MMF shows the phase modulation due to the oscillations of torque and speed. Healthy case is obtained for $\mathrm{m}=0$.

\subsection{Mechanical Defects Signatures in the Current Phase}

Imbalance and misalignment Defects are detectable by appropriate frequency monitoring of the stator current phase (Blodt et al., 2010; Ibrahim et al., 2008; Blodt et al., 2005) Equation 4:

$f_{d}=\left[f_{s} \pm n f_{r}\right]$

The unbalance leads to the increase of the frequencies amplitude defined by $\mathrm{n}=1$ Equation 5 :

$$
f_{\text {unb. }}=f_{S} \pm f_{r}
$$

Most misalignments are a combination of angular and parallel ones. They generate additive amplitudes and frequencies modulated in the stator current Equation 6:

$f_{\text {dés. }}=f_{S}+n f_{r}$

$$
\text { With } \mathrm{n}=2,3,4
$$

Where:

$\mathrm{f}_{\mathrm{d}}=$ The carrier frequency of the mechanical failure

$\mathrm{f}_{\mathrm{s}}, \mathrm{f}_{\mathrm{r}}=$ The power supply frequency and the rotation frequency respectively

\subsection{Mechanical Defects Signatures in the Neutral Current}

The change of the neutral current spectrum in the vicinity of the third order harmonic and its multiples is revealing valuable information about the state of the motor. These information are comparable with those of the phase current or even better Equation 7 and 8:

$$
f_{d .}=\left[h f_{s} \pm k f_{r}\right]
$$

With $: \mathrm{h}=3,5,7, \ldots$ et $\mathrm{k}=1,2,3,4, \ldots \ldots$ 


\subsection{The Combined Defects Detection by the Analysis of the Currents and Neutral Phase}

When it comes to the combination of unbalance and misalignments, all the frequency characteristics of these defects appear in the spectra of the currents and neutral phases, with a prominent increase in amplitudes of the concerned lines.

\subsection{Defects Signatures by Analyzing the Square of the Intensity of the Phase Currents (Pires et al., 2010)}

$$
\left\{\begin{array}{c}
I_{A}=I_{m} \sin (\omega t-\varphi) \\
I_{B}=I_{m} \sin \left(\omega t-\frac{2 \pi}{3}-\varphi\right) \\
I_{C}=I_{m} \sin \left(\omega t-\frac{4 \pi}{3}-\varphi\right)
\end{array}\right.
$$

$$
\begin{aligned}
& \text { IA, IB and IC = The three stator currents } \\
& \begin{aligned}
\text { Im } & \text { Maximum value of the supply phase } \\
& \text { current } \\
= & \text { Supply frequency } \\
\omega & =\text { The phase angle } \\
\varphi & =\text { Time variable }
\end{aligned}
\end{aligned}
$$

In the 3D stator current pattern, also we denote a circle centered at the origin of the coordinates, for ideal condition where its radius $\mathrm{R}$ is Equation 9:

$$
R^{2}=I_{A}^{2}+I_{B}^{2}+I_{C}^{2}
$$

The obtained orbits have ellipsoidal, polygonal or hypocycloidal shapes according on the nature of the defect that occur on the drive. Thus, a visual interpretation of the patterns is affiliated for every type of fault.

\section{DESCRIPTION OF THE EXPERIMENTAL SETUP AND TESTING CAMPAIGNS}

A test rig was required for the experimental study of imbalance, parallel and angular misalignment mechanical defects whether simple or combined that could affect asynchronous motor based electrical drives during their functioning.

It consists essentially of an aggregate of electrical machines (Fig. 1) consisting of an asynchronous motor (4.05 kW, $1430 \mathrm{r} / \mathrm{min}, 220 \mathrm{~V} / 380 \mathrm{~V}, 7.5 / 13 \mathrm{~A} ; 50 \mathrm{~Hz})$. Coupled to a DC generator $(4 \mathrm{~kW}, 220 \mathrm{~V} ; 14 \mathrm{~A} ; 1500$ $\mathrm{trs} / \mathrm{mn}$ ) filler material.

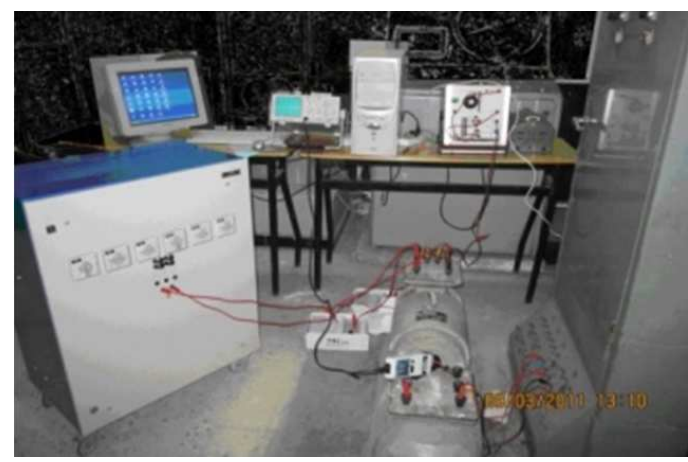

Fig. 1. Photo of engine bench dedicated to diagnosis

The acquisition signals for the diagnosis were made by the following apparatus:

- A collection of two-channel brand B \& K Vibro data type: VT60: with 02 sensors

- An accelerometer brand SCHENCK Type: AS-065.

- A current clamp

- A Hamlet digital oscilloscope to acquire current and file transfer via the serial portHM507, to the computer

The data processing is done using MATLAB software for signal analysis. Unbalanced mechanical defects, parallel misalignment, angular misalignment and their combination were created artificially. A mass of 50 grams fixed on the motor shaft has been used for the intentional creation of the unbalance. The parallel and angular misalignments were exercised virtually lifting the induction motor using plates $2 \mathrm{~mm}$ under the four brackets for parallel and only under the two front legs or back for angular misalignment. Then we proceeded to the combination unbalanced faults with axial and angular misalignments on aggregate. This latter was subjected to load variations (in vacuum then 50 and $75 \%$ ). Only half load tests have been shown to avoid cluttering the document.

\section{DISCUSSION OF THE TEST CAMPAIGN RESULTS}

During the operation of the machine aggregate, in the lack of the defects targeted by our study, no significant alteration was observed in the content of the current spectrum of the stator phase. Only sidebands around the prominent harmonics are found even when the machine is healthy. This is due to the ideal theoretical conditions which are not met and manufacturing imperfections. When the motor operates in degraded mode due to an unbalance of $50 \mathrm{~g}$, the presence of lines at 26.17 and $73.83 \mathrm{~Hz}$ frequency reflects this fault and verifies the relation (4) with $1 \mathrm{f}_{\mathrm{r}}=23.83 \mathrm{~Hz}$. 
In the case of misalignment, a clear emergence appears on line at $\mathrm{f}_{\text {dés. }}=50+2 \mathrm{f}_{\mathrm{r}}$ of $97.76 \mathrm{~Hz}$ with an more attenuated prominent amplitude for angular misalignment. We should note that the lines with frequencies $f_{\text {unb. }}=f_{S} \pm f_{r}$ however, are attenuated, they still exist in the current spectrum, but they are overlapped by those of misalignments. When the machine aggregate is subjected to the combination of unbalance and misalignment defects, the frequency signatures $50 \pm \mathrm{f}_{\mathrm{r}}$ and $50+2 \mathrm{f}_{\mathrm{r}}$ appear together in the spectrum of the phase current with a significant arithmetic addition of their magnitudes.

Regarding the spectrum of the neutral current (Fig. 5), a weakening of the amplitude of the fundamental (50 $\mathrm{Hz})$, the preponderance of the $3 \mathrm{rd}$ harmonic $(150 \mathrm{~Hz})$ and the 5th harmonic $(250 \mathrm{~Hz})$ is observed. In the presence of imbalance defects (Fig. 5b), sidebands are noticed around the relevant harmonics of order $3,5,7,9$ with the emergence of frequencies 226, 274, 374 and 326 Hz. It should be noted that more apparent sidebands are induced by the unbalance defect at $5 f_{s} \pm f_{r}$ et $7 f_{s}+f_{r}$. Due to a misalignment in the drive, the spectrum of neutral current (Fig. 6a) reveals the prominent emergence of lateral lines at frequencies $5 \mathrm{f}_{\mathrm{s}} \pm 2 \mathrm{f}_{\mathrm{r}}$, as well as the frequency $5 \mathrm{f}_{\mathrm{s}} \pm \mathrm{f}_{\mathrm{r}}$, but with a slight increase in their amplitudes. The frequencies $3 \mathrm{f}_{\mathrm{s}} \pm 2 \mathrm{f}_{\mathrm{r}}, 5 \mathrm{f}_{\mathrm{s}} \pm \mathrm{f}_{\mathrm{r}}, 5 \mathrm{f}_{\mathrm{s}} \pm 2 \mathrm{f}_{\mathrm{r}}$ and $7 f_{s} \pm f_{r}$ are introduced into the spectrum of the neutral current as a result of the combined fault of unbalance and misalignment (Fig. 6b).

A significant arithmetic addition of the amplitudes of the frequencies that correspond to unbalance and misalignment is noted. It is worth mentioning that the effect of the load variation had no significant effect on all failures. The faults signatures can even be hidden through the increase in the load by using the noise damping.

The faults signatures can even be hidden through the increase in the load by using the noise damping. When

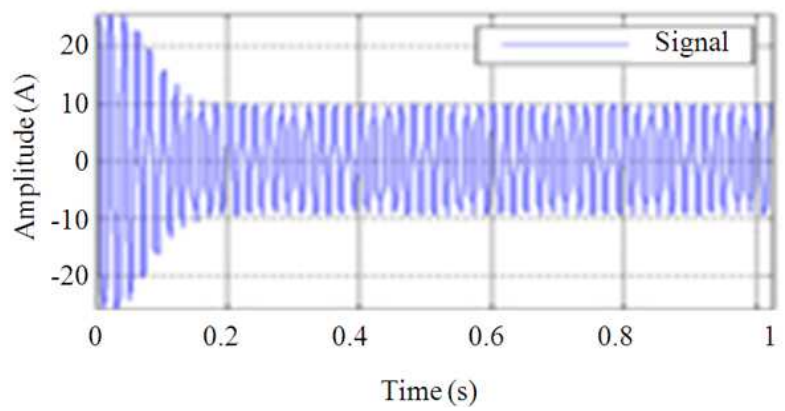

(a) the drive via the motor is not subject to any defect (healthy), the pattern obtained by the $3 \mathrm{D}$ representation of the square of the vector resulting from $\left(\mathrm{I}_{\mathrm{A}}{ }^{2}+\mathrm{I}_{\mathrm{B}}{ }^{2}+\mathrm{I}_{\mathrm{C}}{ }^{2}\right)$ takes the form of an orbit not completely circular (Fig. 7), but rather ellipsoidal. This is explained by the absence of ideal operating conditions and manufacturing imperfections of the machine aggregate. This ellipsoid is strongly narrowed when the motor functioning is degraded by the presence of imbalance (Fig. 8). The pattern interpreting the default tends toward a hypocycloid shape (Fig. 9) if a misalignment affects the electric drive. This hypocycloidal geometry narrows enormously if the unbalance merges with the misalignment (Fig. 10) and gives the impression that the imbalance tends to hide the misalignment. These visual signatures in patterns accompanied by spectral analysis to help decide on the type and nature.

\section{EXPOSITION OF THE EXPERIMENTAL RESULTS}

\subsection{By the processing of the Phase Current}

Figure 2 shows the temporal characteristic and the current spectrum for healthy case. In Fig. 3, the three spectra of the stator current phase are shown (Fig. 3a) on the left, with the spectral content when the motor is subject to an imbalance. At the middle (Fig. 3b) and the left (Fig. 3c), spectral contents are respectively exposed when the motor faces a parallel misalignment and then an angular misalignment. Fig. 4a and $\mathbf{4 b}$ show the spectra and the emergence of the characteristic frequencies of the combination of the unbalance with parallel misalignment and angular misalignment respectivel.

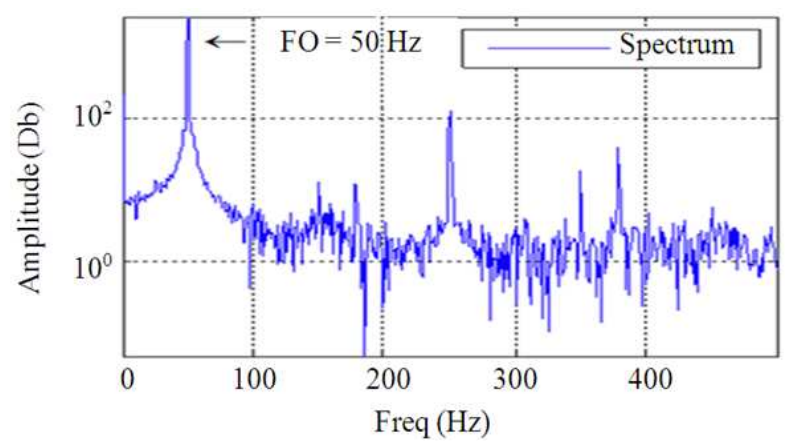

(b)

Fig. 2. Temporal characteristic of current (a) and its spectrum (b) for Healthy engine 


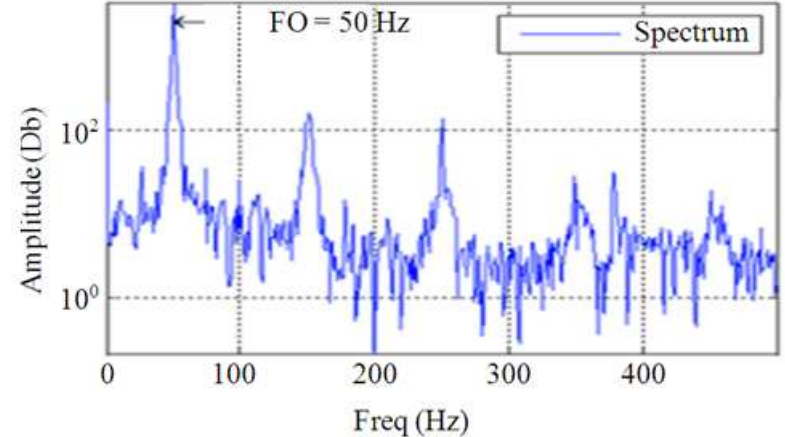

(a)

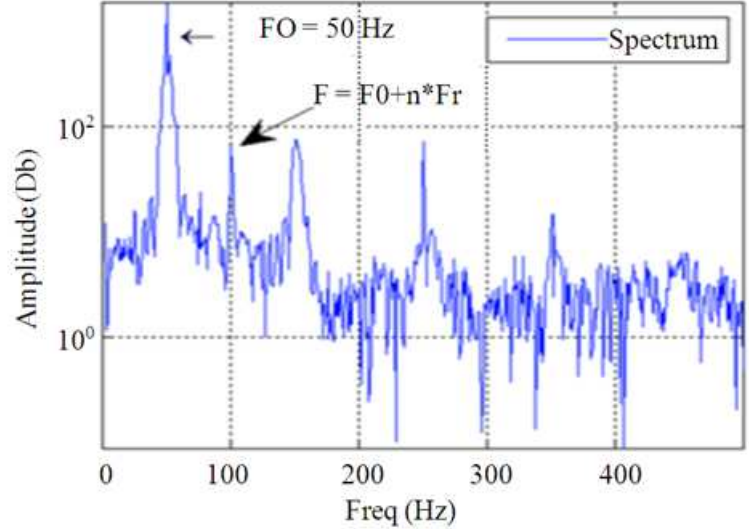

(b)

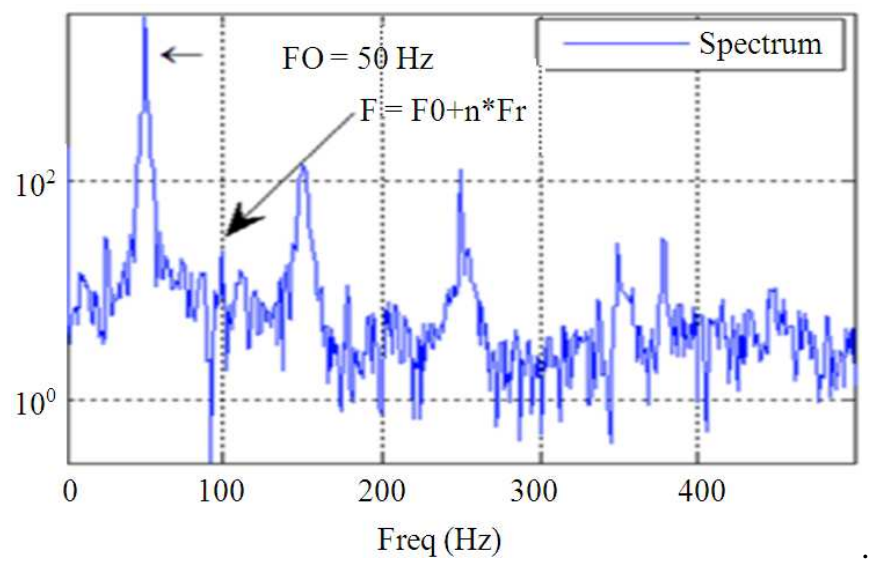

(c)

Fig. 3. Spectrum of the stator current of motor in the presence of mechanical defects: (a) Unbalance, (b) parallel misalignment, (c) Angular misalignment

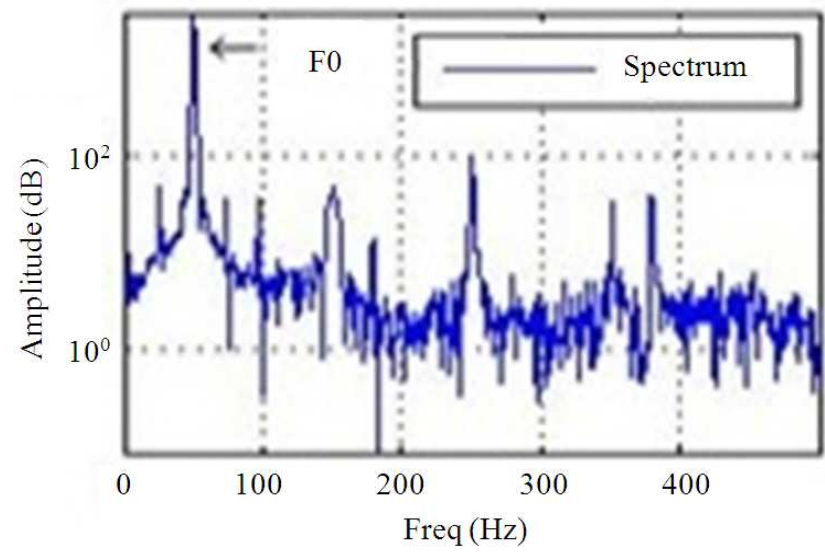

(a)

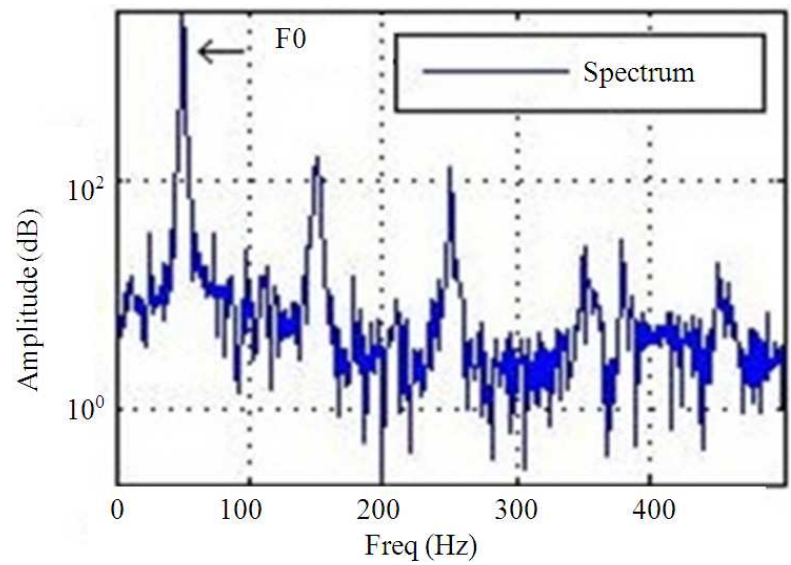

(b)

Fig. 4. Spectrum of the stator current of the motor in the presence of combined mechanical defects: (a) Unbalance and parallel misalignment, (b) unbalance and angular misalignment 
Bouras A. Karim et al. / American Journal of Applied Sciences 11 (6): 994-1004, 2014

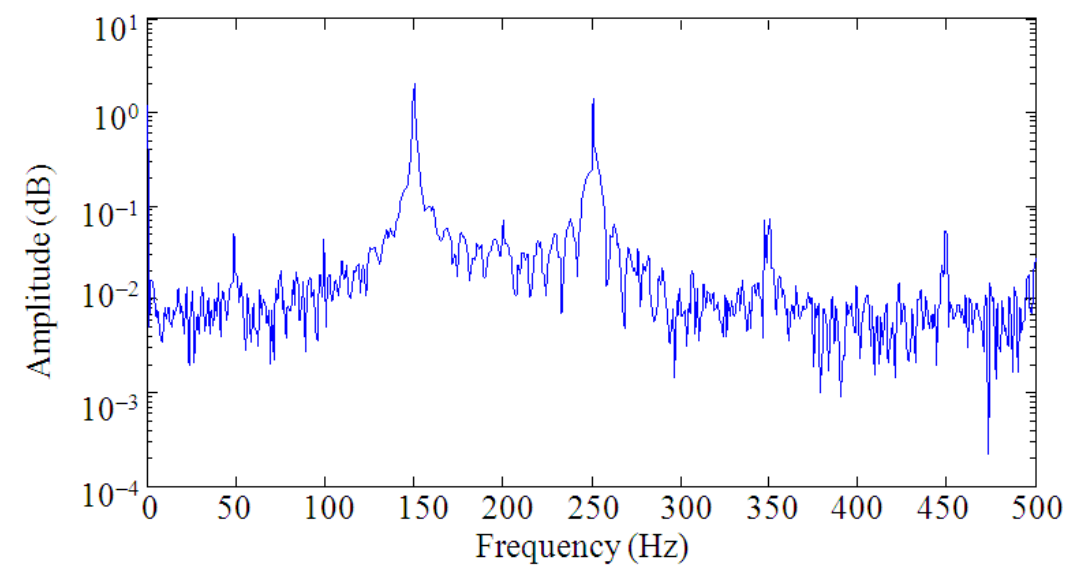

(a)

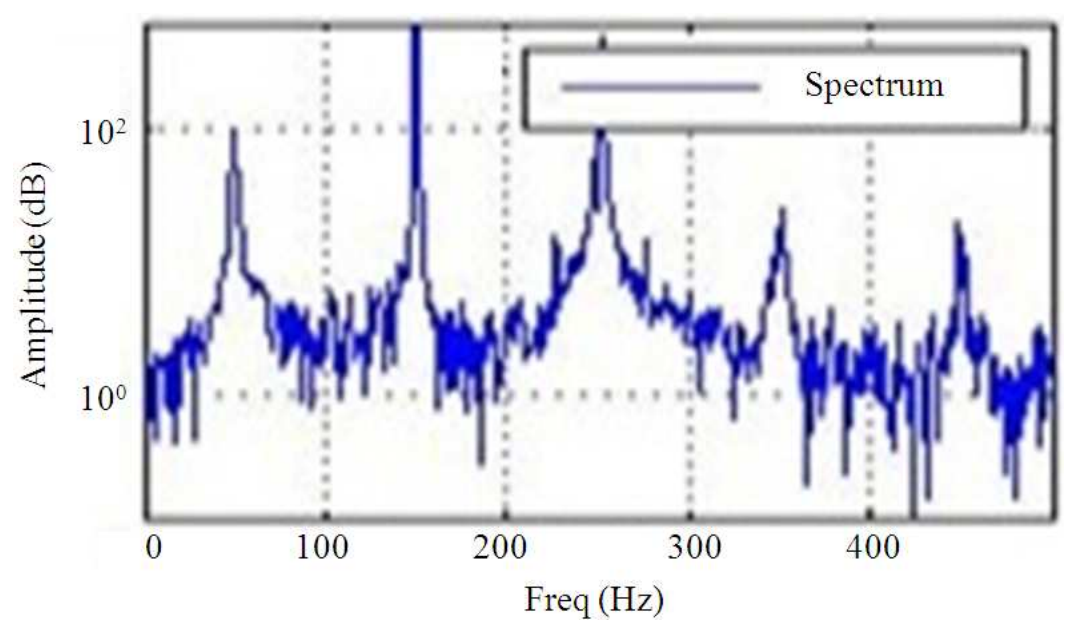

(b)

Fig. 5. Spectrum of the neutral current: (a) A healthy state, (b) failure to unbalance

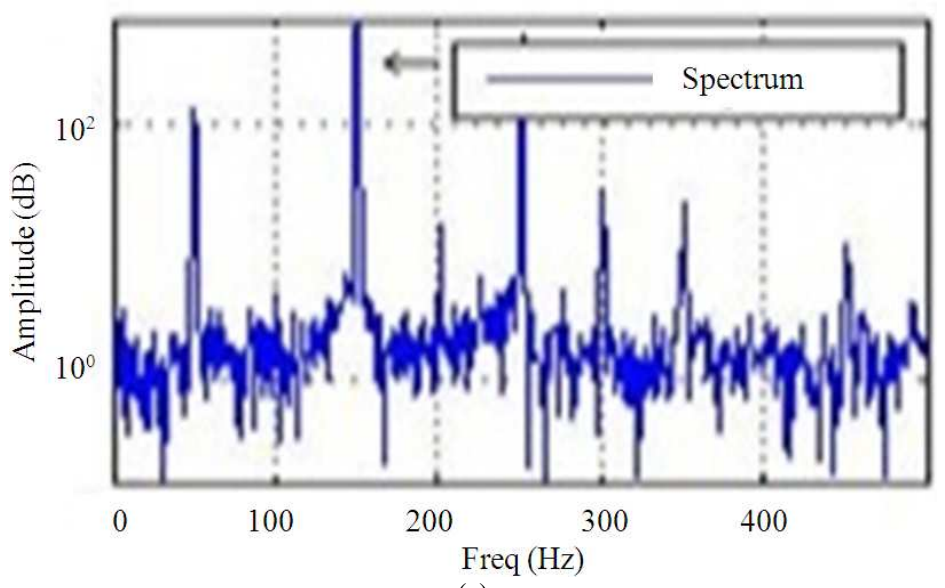

(a) 


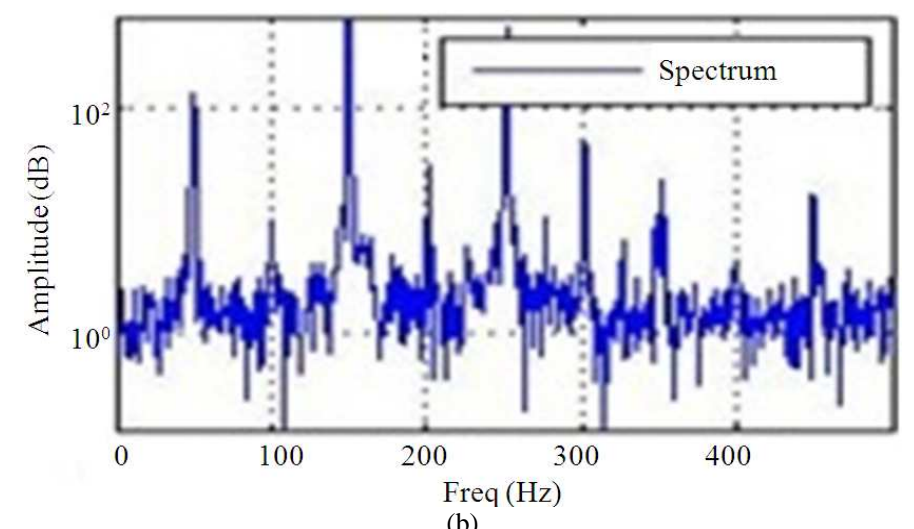

Fig. 6. Spectrum of the neutral current: (a) Failure to misalignment, (b) failure to combined unbalance and misalignment

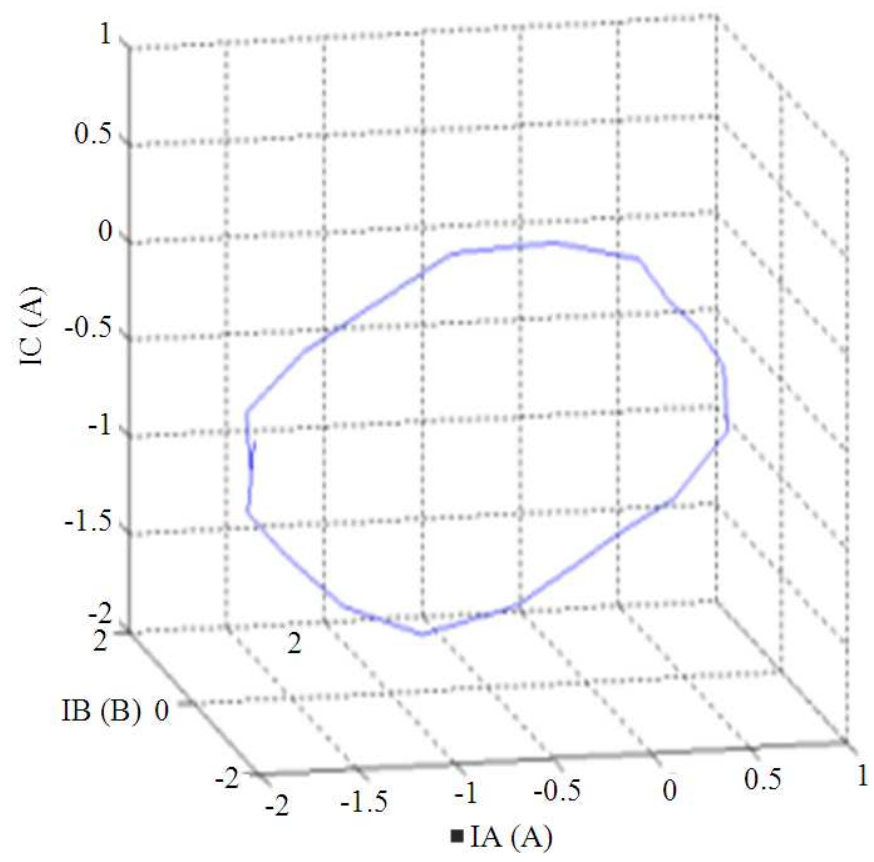

Fig. 7. Healthy motor pattern

\subsection{By the Treatment of the Neutral Current.}

Figure 5a shows the spectrum in the case of nondegraded machine, where the preponderance of the third harmonic followed by the fifth harmonic and the fundamental mitigation are noticed. The

Figure 5b shows the spectrum of the neutral current in the case of faulty asynchronous motor in the presence of unbalance on its mechanical transmission shaft. Figure 6a illustrates the spectrum of neutral current for the defectiveness of the alignment. Figure 6b is about the frequencies introduced by the combined defects of unbalance and misalignment in the spectrum of the neutral current.

\subsection{The Processing of the Square Intensities of the Three Phase Currents}

Figure 7 shows the pattern obtained by the 3Dspatial representation of the model when the drive, via the motor, is not subject to any defect (healthy). Figure 8-10 show the representation of the patterns during the operation of the drive system, in the presence of an unbalance, misalignment and then a combination of these two defects. 
Bouras A. Karim et al. / American Journal of Applied Sciences 11 (6): 994-1004, 2014

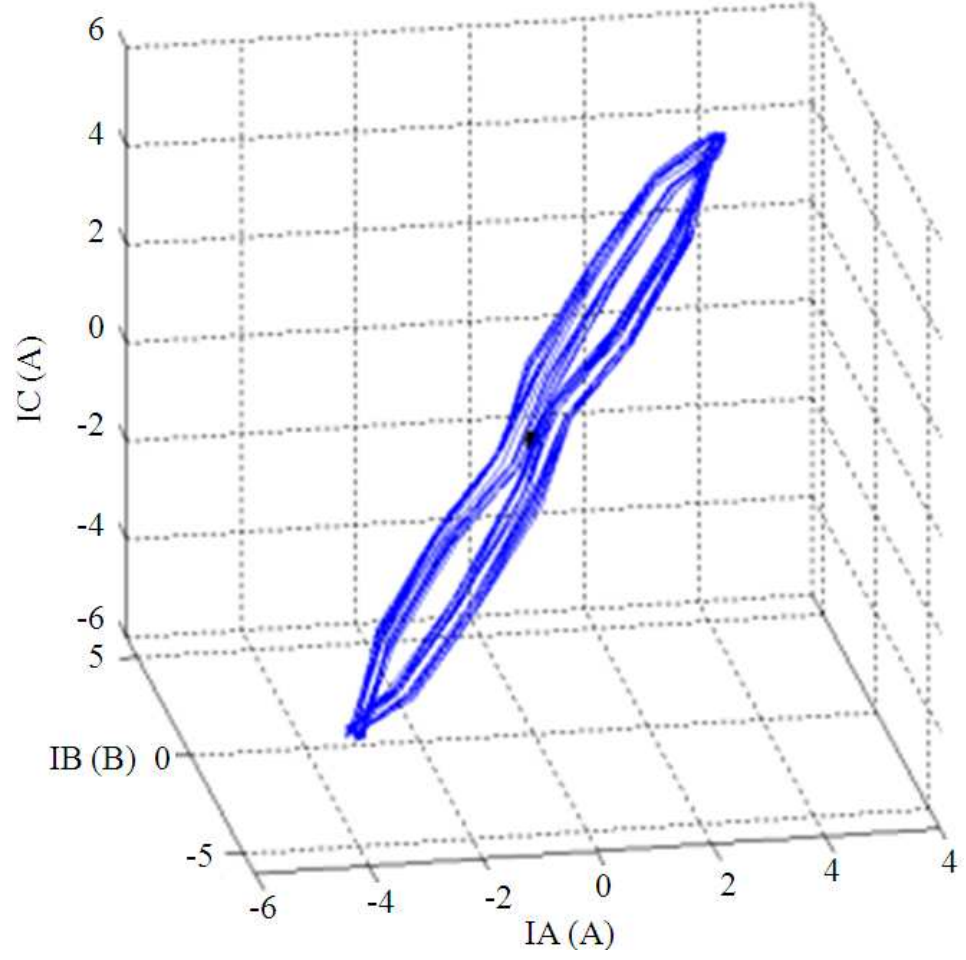

Fig. 8. Unbalance defect pattern

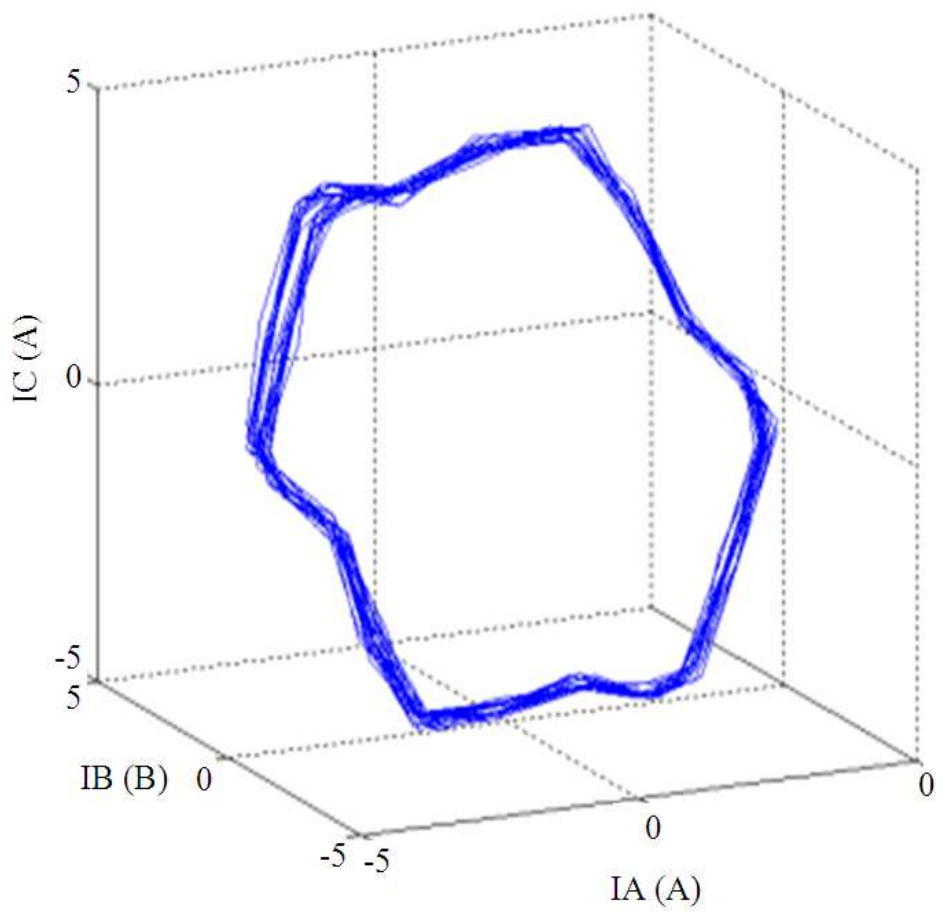

Fig. 9. Pattern representing the absence of misalignment: (A) 3D view (B) 2D orthogonal view 


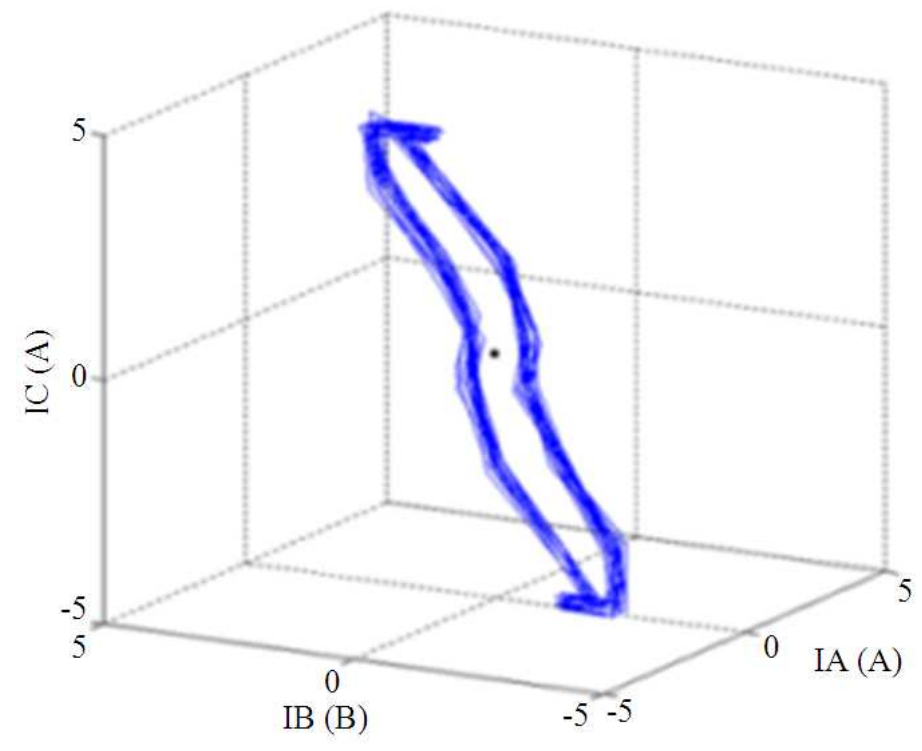

Fig. 10. Pattern marking the default Combined unbalance and misalignment: A. 3D view b. orthogonal 2D view

\section{CONCLUSION}

In this experimental investigation, the diagnosis of isolated and combined mechanical failures have been discussed. Diagnostic capacities and remote detection without physical contact with the faulty machine components have become more robust. The experimental results confirm that the studied mechanical defects generate additional amplitudes and frequencies in the supply current signal. These simple and combined mechanical defects are easily detectable and identifiable through the analysis of the phase current and neutral current (FFT) supplemented by a visual reading of the patterns that correspond to each type of anomaly. The implementation of this simple and low-cost methodology characterized by an easily accessible interpretation of results can benefit from a wide range of use. It can contribute to the development of an expert systems for the diagnosis of single and multiple mechanical failures affecting the electric drives.

\section{REFERENCES}

Bindus, S. and T.V. Vinod, 2014. Diagnosis of internal faults of three phase cage squirrel induction motor-a review. Proceedings of the International Conference on Advances in Energy Conversion Technologies, Jan. 23-25, IEEE Xplore Press, Manipal, pp: 48-54. DOI: 10.1109/ICAECT.2014.6757060
Blodt, M., J. Faucher, B. Dagues and M. Chabert, 2005. Mechanical load fault detection in induction motors by stator current time-frequency analysis. Proceedings of the IEEE International Conference on Electric Machines and Drives, May 15-15, IEEE Xplore Press, San Antonio, TX., pp: 1881-1888. DOI: 10.1109/IEMDC.2005.195977

Blodt, M., P. Granjon, B. Raison and J. Regnier, 2010. Mechanical Fault Detection Induction Motor Drives. In: Through Stator Current Monitoring-Theory and Application Examples, Zhang, W., (Ed.)., ISBN-10: 9533070377, pp: 451-487.

Bonnett, A. H. and C. Yung 2008. Increased effeciency versus increased reliability. IEEE Industry Applic. Magazin, 14: 29-36. DOI: 10.1109/MIA.2007.909802

Cameron, J.R., W.T. Thomson and A.B. Dow, 1986. Vibration and current monitoring for detecting air gap large induction motors. IEE Proc. Electric Power Applic., 133: 155-163. DOI: 10.1049/ipb:19860022

Concari, C., G. Franceschini and C. Tassoni, 2010. A MCSA procedure to diagnose low frequency mechanical unbalances in induction machines. Proceedings of the 19th International Conference on Electrical Machines, Sept. 6-8, IEEE Xplore Press, Rome. DOI: 10.1109/ICELMACH.2010.5607931 
Dorrell, D.G., W.T. Thomson and S. Roach, 1997. Analysis of airgap flux, current and vibration signals as a function of the combination of static and dynamic air gap eccentricity in 3-phase induction motors. IEEE Trans. Ind. Applic., 33: 24-34. DOI: 10.1109/28.567073

Ibrahim, A., F. Guillet, M. Elbadaoui and F. Bonnardot, 2008. Techniques to estimate the instantaneous frequency with an aim of diagnosis induction machines faults. Proceedings of the 34th IEEE Annual Conference Industrial Electronics, Nov. 10-13, IEEE Xplore Press, Orlando Florida, USA., DOI: 10.1109/IECON.2008.4757985

Kazzaz, S.A. and G.K. Singh, 2003. Experimental investigations on induction machine condition monitoring and fault diagnosis using digital signal processing techniques. Electric Power Syst. Res., 65: 197-221. DOI: 10.1016/S03787796(02)002274

Li, W. and C.K. Meshefske, 2006. Detection of induction motor faults: a comparison of stator current, vibration and acoustic methods. J. Vibration Control, 12: 165188. DOI: $10.1177 / 1077546306062097$

Martınez-Morales, J.D., E. Palacios and D.U. CamposDelgado, 2010. Data fusion for multiple mechanical fault diagnosis in induction motors at variable operating conditions. Proceedings of the 7th International Conference on Electrical Engineering, Computing Science and Automatic Control, Sept. 8-10, IEEE Xplore Press, Tuxtla Gutierrez, Mexico. DOI: 10.1109/ICEEE.2010.5608632

Martins, J.F., V.F. Pires and T.G. Amaral, 2011. Induction motor fault detection and diagnosis using a current state space pattern recognition. Patt. Recognit. Lett., 32 : 321-328. DOI:10.1016/j.patrec.2010.09.010

Medoued, A., A. Metatla, A. Boukadoum, T. Bahi and E.A. Hadjadj, 2009. condition monitoring and diagnosis of faults in the electric induction motor. Am. J. Applied Sci., $\quad$ 6: 1133-1138. DOI: 10.3844/ajassp.2009.1133.1138

Oumaamar, M.E.K., A. Khezzar, M. Boucherma, H. Razik and R.N. Andriamalala et al., 2007. Neutral voltage analysis for broken rotor bars detection in induction motors using Hilbert transform phase. Proceedings of the 42nd IEEE Conference on Industry Applications, Sept. 21-27, IEEE Xplore Press, New Orleans, USA. DOI: 10.1109/07IAS.2007.295

Oumaamar, M.E.K., H. Razik and A. Khezzar, 2009. Experimental investigation of stator current signature in defective induction motor. Proceedings of the 35th IEEE Annual Conference of Industrial Electronics, Nov. 3-6, IEEE Xplore Press, Porto, pp: 3443-3448. DOI: $10.1109 /$ IECON.2009.5415184
Pandey, K.K., P.H. Zope and S.R. Suralkar, 2012. Review on fault diagnosis in three-phase induction motor. Int. J. Comput. Applic.

Patel, T.H. and K. Darpe, 2009. Experimental investigations on vibration response of misaligned rotors. Mech. Syst. Signal Proces., 23: 2236-2252. DOI: 10.1016/j.ymssp.2009.04.004

Pires, V.F., J.F. Martinsm and A.J. Pires, 2010. Eigenvector/eigenvalue analysis of a 3D current referential fault detection and diagnosis of an induction motor. Energy Convers. Manage., 51: 901-907. DOI: 10.1016/j.enconman.2009.11.028

Sahraoui, M., A. Ghoggal, S. Zouzou and M. Benbouzid, 2008. Dynamic eccentricity in squirrel cage induction motor-Simulation and analytical study of its spectral signature on stator currents. Simulat. Modell. Pract. Theory, 16: 1503-1513. DOI: 10.1016/j.simpat.2008.08.007

Scheffer, C. and P. Girdhar, 2004. Pratical Machinery Vibration Analysis and Predictive Maintenance. 1st Edn., Newnes, ISBN-10: 0750662751, pp: 272.

Sekhar, A.S. and B.S. Prabhu, 1995. Effects of coupling misalignment on vibrations of rotating machinery. J. Sound Vibrat., 185: 655-671. DOI: 10.1006/jsvi.1995.0407

Sethom, H.B.A. and M.A. Ghedamsi, 2012. Multi resolution analysis based effective diagnosis of induction motors. Am. J. Applied Sci., 9: 624-632. DOI: 10.3844/ajassp.2012.624.632

Chaudhury, S.B., M. Sengupta and K. Mukherjee, 2013. Experimental study of induction motor misalignment and its online detection through data fusion. IET Electr. Power Applic., 7: 58-67. DOI: 10.1049/iet-epa.2012.0129

Thomson, W.T. and M. Fenger, 2001. Current signature analysis to detect induction motor faults. IEEE Industry Applic. Magazine, pp: 26-34. DOI: 10.1109/2943.930988

Thorsen, O.V. and M. Dalva, 1998. Failure identification and analysis for high voltage induction motors in petrochemical industry. Proceedings of the 33rd IAS Conference Annual Meeting on Industry Applications, Oct. 12-15, IEEE Xplore Press, pp: 291-298. DOI: 10.1049/cp:19971048

Thorsen, O.V. and M. Dalva, 1995. A survey of faults on induction motors in offshore oil industry, petrochemical industry, gas terminals, and oil refineries. IEEE Trans. Ind. Applic., 31: 1186-1196. DOI: $10.1109 / 28.464536$ 
Wongsuwan, T., P. Tangamchit, C. Prapanavarat and M Pusayatano, 2006. Motor misalignment detection based on hidden markov model. Proceedings of the 6th International Symposium on Communications and Information Technologies, Oct. 18-Sept. 20, Bangkok, pp: 422-427. DOI: 10.1109/ISCIT.2006.339981
$\mathrm{Xu}$, M. and R.D. Marangoni, 1994. Vibration analysis of a motor-flexible coupling rotor system subject to misalignment and unbalance, Part I: Theoretical model and analyses. J. Sound Vibrat., 176: 663-679.

DOI: 